be sufficient to generate hierarchies. If a strong enough relationship existed between backward association and subsequent forward association, the second step could be dropped. Unfortunately, such does not obtain $(r=+.36)$, possibly for several reasons. Rogers's Ss were asked to produce a stimulus for a word, not a stimulus which would selectively evoke that word as a primary, nor even a stimulus which would not evoke other competing responses. Hence, $S$ may list red as a stimulus for apple; yet when asked to respond in discrete free association to red, he may reply with blue. Obviously, continued associations might be more sensitive indicators under these circumstances. Apple might then be elicited on the second, third, or later presentation of red. It might be desirable, then, to use highly trained rather than naive $S s$ to produce potential stimuli via backward association, thereby decreasing some of the noise in the system. A further problem exists, though, with respect to probability as a response measure. For both backward- and forward-association norms, probability of response is based on relative frequency of occurrence among events. An index of absolute strength of habit is badly needed, and would be much more useful.

Assessment of stimulus hierarchies, while feasible, exceeds by an order of magnitude the difficulty of obtaining norms on response distributions. None of the approaches presented in this paper is without strong disadvantages, and no technique presently available insures the location of all strong stimuli for a given word. The adequacy of information gained by any of the techniques listed will depend on the user's specific needs. It is, then, reasonable to wonder what need exists for data on stimulus hierarchies. One cannot foresee, when collecting norms of any sort, the extent of their eventful applications. Surely applications of the Russell-Jenkins (1954) norms and the Thorndike-Lorge (1944) word count have far exceeded author's expectations. At the moment, though, certain applications are already apparent in (a) pursuing Deese's (1961) attack on meaning, (b) pairedassociates training through manipulation of associative S-R strength via E's choice of stimuli, response components held constant. (c) pursuing the knotty problem of verbal stimulus generalization, and (d) elucidation of rules for constituent synthesis in verbal behavior (a very nagging problem for most stimulus-response theorists) via use of multiple stimuli to elicit verbal responses, as set forth by Miller (1965) and Underwood (1966).

\section{REFERENCES}

BILODEAU, E. A., FOX, P. W., \& BLICK, K. A. Stimulated verbal recall and analysis of sources of recall. J. verbal Leam. verbal Behav., 1963, 2, 422-428.

BLICK, K. A. Cultural primaries as a source of interference in short-term verbal retention. J. exp. Psychol, 1965, 69, 246-250.

COFER, C. N. On some factors in the organizational characteristics of free recall A mer. Psychologist, 1965, 20, 261-272.

COLEMAN, E. B. The association hierarchy as an indicator of extr: experimental interference. J. verbal Lean. verbal Behav., 1963, 2 , $417-421$.

DEESE, J. On the structure of associative meaning. Psychol. Rev., 1962 69, 161-175.

JENKINS, J. J. Mediated associations: Paradigms and situations. In C. N. Cofer and B. S. Musgrave (Eds), Verbal behavior and learning. New York: McGraw-Hil, 1963. Pp. 210.245.

MLLER, G. A. Some preliminaries to psycholinguistics. Amer. Psychologist, 1965, 20, 15-20.

MINK, W. D. Semantic generatization as related to word association. Tech. Rep No. 17, 1957, Contract No. N8onr-66216, Office of Naval Research and University of Minnesota.

ROGERS, C. A., JR. Associative hierarchies, stimulus sampling, and differential recall. Unpublished doctoral dissertation, Tulane University, 1965.

ROSENBERG, S. Recall of sentences and function of syntactic and associative habit. J. verbal Learn. verbal Behav., 1966, S, 392-396.

RUSSELL, W. A., \& JENKINS, J. J. The complete Minnesota norms for responses to 100 words from the Kent-Rosanoff Word Association Test. Tech. Rep. No. 11, 1954, Contract No. N8onr-66216, Office of Naval Research and University of Minnesota.

SNELL, G. R. Associative stimulus hierarchies. Unpublished master's thesis, University of Arizona, 1966.

THORNDIKE, E. L., \& LORGE, I. The teacher's word book of 30,000 words New York: Teacher's College, 1944.

UNDERWOOD, B. J. Interference and forgetting. Psychol. Rev., 1957, 64, 4960.

UNDERWOOD, B. J. Motor-skills learning and verbal leaming: Some observations In E. A. Bilodeau (Ed.), Acquisition of skill. New York: Academic Press, 1966. Pp. 489-516.

UNDERWOOD, B. J., \& POSTMAN, L. Extraexperimental sources of interference in forgetting. Psychol. Rev., 1960, 67, 73-95.

WEBSTER'S seventh new' collegiate dictionary. (7th ed.) Springfield, Mass: G. \& C. Merriam, 1967.

NOTE

1. Preparation of this manuscript was supported in part by NASA Grant NGR 03-002-091.

\title{
GSR amplitude instead of GSR magnitude: Caveat emptor!'
}

\section{H. D. KIMMEL, DEPARTMENT OF PSYCHOLOGY, OHIO UNIVERSITY, Athens, Ohio 45701}

Size of GSR made by 300 Ss to 20 repetitions of a visual stimulus is presented as mean magnitude and mean amplitude, illustrating that the amplitude method (averaging only those responses which are greater than zero/ is susceptible to distortion resulting from a sistematic elimination of Ss who initially make small responses. From trial to trial, the amplitude function comes more and more to be due to the behavior of Ss who initially make large responses, Even though the latter Ss' responses actually reduce across trials, the amplitude function rises. Magnitude (including zeroes) does not suffer from this distortion. It is suggested that the definition of a zero response is the source of the problem.
In a recent discussion of methodological problems in classical conditioning, Gormezano (1966) has urged that researchers using the galvanic skin response (GSR) should use amplitude rather than magnitude of the response in describing their results. His argument is based on the proposition that "it is desirable to make frequency and extent measures as independent as possible" ( $p$. 386). Magnitude measures are typically obtained by summing the reactions of all of the Ss on a particular occasion and dividing by the total number of Ss; amplitude measures differ in that the same sum is divided by only the number of Ss who actually made non-zero reactions on that occasion. On the basis of this distinction, Morrow \& Keough (in press), Prokasy \& Ebel (1964, 1967), and Prokasy, Fawcett, \& Hall (1962) have adopted the procedure of reporting amplitude and magnitude measures separately. 


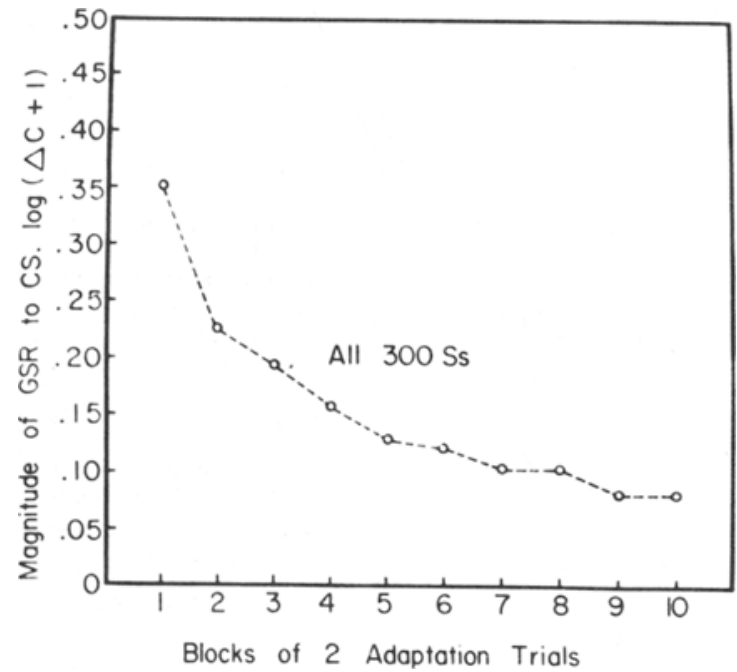

Fig. 1. Mean GSR magnitude in response to 20 repetitions of a visual stimulus, presented in blocks of two trials $(N=300$ at each point).

Rather than producing a clarification of the issues involved in GSR studies, as is implied by Gormezano (1966) and by Prokasy \& Ebel (1967), the incautious use of amplitude measures may result in considerably greater confusion. When different Ss' responses are averaged on different trials, the outcome of even familiar experimental procedures may be downright misleading. To illustrate this point, Fig. 1 presents average GSR magnitude data obtained from the responses of 300 college sophomores who received 20 presentations of a dim white light during a habituation series preceding a conditioning session (Kimmel, 1964). Each point represents a pair of trials and an $\mathrm{N}$ of 300 . The function, of course, depicts the well-known decline in responding characteristic of habituation to the same stimulus under repeated presentations.

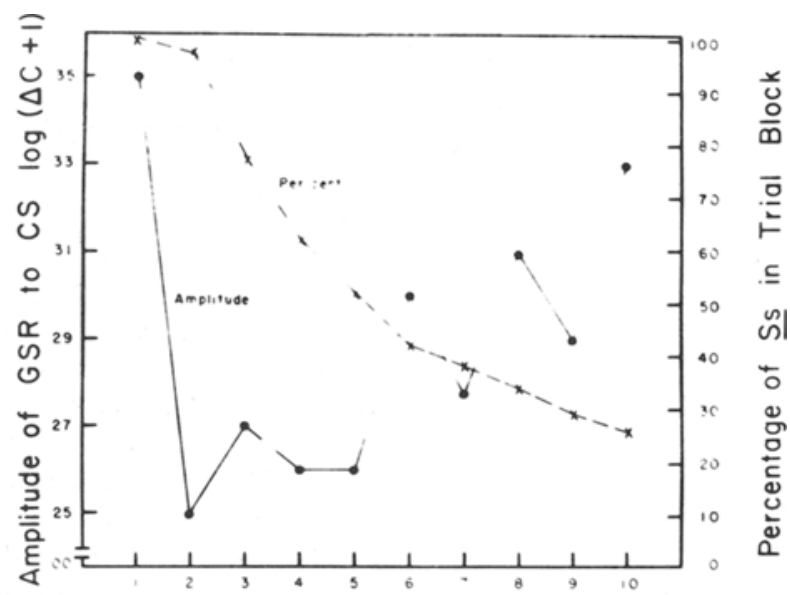

Blocks of 2 Adaptation Trials

Fig. 2. Mean GSR amplitude in response to $\mathbf{2 0}$ repetitions of a visual stimulus, presented in blocks of two trials (per cent curve shows decline in number of $S s$ at each point. from $N=300$ to $N=72$ ).
Figure 2 shows what happens to these data when an amplitude rendition is cmployed. The solid curve in Fig. 2. labeled "amplitude." shows the average size of the response in each two-trial block of only those Ss who made a response on at least one of the two trials. The dashed curve, labeled "per cent," indicates the way in which the number of $S$ s whose responses were included in each amplitude point declined across the 20 trials. From inspection of only the "amplitude" curve in Fig. 2, one might conclude that the habituation process is characterized by an initial marked drop in the size of the response, for about four trials or so. followed by a steady rise in response size, until it retums almost to its original level.

What has happened. of course. is that a sistematic factor differentiates among the Ss from block to block. That is, as one moves from left to right in Fig. 2. the Ss whose responses have dropped to zero and. thus. are no longer contributing to the average value, are $S s$ who even initially make small responses. As these Ss' responses drop out (i.e.. become zero). the contribution of the Ss who make large responses receives greater and greater weight. making the average value tend to rise accordingly. That the amplitude curce shown in Fig. 2 is not an accurate reflection of the habituation process of any of the $\mathrm{Ss}$ is anply demonstrated in Fig. 3, which shows the GSR magnitude-amplitude curve of only those Ss who actually responded in all 10 blocks of trials. As Fig. 3 indicates. the $72 \mathrm{Ss}$ who responded on each of the 10 blocks of trials showed a steady, albeit small. decline in response size.

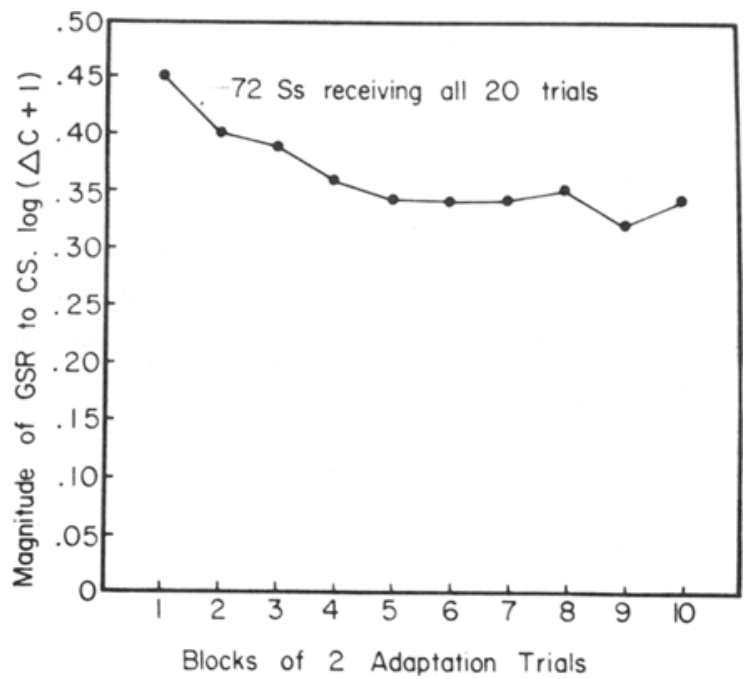

Fig. 3. Mean GSR magnitude-amplitude in response to 20 repetitions of a visual stimulus, presented in blocks of two trials for only those 72 Ss who responded in each block.

One of the reasons why the use of GSR amplitude can be misleading in the foregoing type of situation (as well as in conditioning or extinction situations) is that many of the factors that influence the size of the GSR (e.g. . conditioning or extinction trials) also influence its latency. Since most sophisticated GSR researchers employ an explicit temporal response criterion (e.g. the 5-sec period following the onset of the conditioned stimulus), experimental operations that have the effect of attenuating the size of the response over trials may also shift the response out of the latency interval being used. Thus. if the response latency gets long enough (even before zero size is 
reached), the response will be scored as a zero. The sooner this happens, the earlier this small reaction will be omitted from an average amplitude curve.

In addition, another reason why caution should be employed in using and interpreting amplitude renditions of GSR data is the simple fact that the definition of a zero response is actually quite arbitrary. A zero response at one gain level of the GSR amplifier may be a non-zero response at a higher level, and vice versa. The same point can, of course, be made regarding the level of "amplification" of the visual system of the person who measures the responses. Even if there were a persuasive argument in support of singling out zero size as being in a class entirely apart from all other sizes of response (which, as is noted below, is far from being satisfactorily settled), the arbitrariness of most definitions of zero in practice would indicate that omitting zeroes may be a greater error than including them (the latter, at worst, resulting in a truncated measurement scale near its lower end).

At bottom, the definition of response probability is what clouds the entire magnitude-amplitude issue. In the case of very short latency skeletal responses, baseline activity prior to an observed response does not play an important role in response definition. However, autonomically mediated responses such as the GSR are known to reflect the law of initial value, for one thing, and, for another, do not lend themselves quite as easily to discrete identification; GSRs may be both very small and very large. In the case of an eyeblink, as this response is typically recorded, a dichotomous categorization of occurrence or nonoccurrence can be made almost errorlessly. When the response occurs, it occurs with sufficient strength to preclude concern regarding differentiating it from zero response. In this situation, zero response is non-response. Ignoring fluctuations in the size of the eyelid response (i.e., lumping all responses together by giving them all a score of 1 and all non-responses a score of 0 ) reasonably reflects the reality of the occurrence-non-occurrence dichotomy. Extension of this logic to the GSR, which is actually what Gormezano and Prokasy suggest, ignores the fact that the distribution of sizes of the GSR is not of this bimodal type. The GSR is a continuously variable quantity and a very, very small response is, merely, one that is slightly larger than a zero response. A difference in amount is all that there is between them. The use of the amplitude measure assumes that zero response represents an entirely different kind of event (or non-event).

The parties to this controversy would surely agree that at least some portion of its resolution ought to be achieved empirically. Do different empirical laws describe the relationship between important independent variables and GSR magnitude as compared with GSR amplitude? To date, the following generalization appears to have been supported; those independent variables that have been shown to influence GSR amplitude also influence GSR magnitude (and in a similar fashion). The only exception, to the parenthetical part of this generalization, is found in the kind of comparison illustrated above, when different kinds of Ss are gradually dropped out of the amplitude function and, as a result, it is totally misleading as to the change in size of the GSR across repetitive stimulation. In addition, sometimes an independent variable appears to influence GSR magnitude and probability but not GSR amplitude. To interpret this as meaning that the particular independent variable doesn't influence the size but only influences the occurrence or non-occurrence of the response (Prokasy \& Ebel, 1967), exemplifies the great potential for confusion inherent in the use of this measure. The only way in which this statement could be supported would be in a situation in which it was shown that no systematic tendency for Ss either to drop out or to be included was present. If there were a systematic tendency for Ss to drop out of the function across trials, such as a difference in response-size between early and late drop-outs (small responders, for example, dropping out first), the complex amplitude curve could easily show no effect of the independent variable while both magnitude and probability did. If the responses of only the Ss who respond on every trial are looked at, a function resembling both the magnitude and probability functions will be obtained, as was shown above. But, in this case, magnitude and amplitude would really be the same thing, since there would be no zeroes to omit. What this argument suggests is that a hoped-for empirical resolution of the question may actually be impossible. The question may be resolved a priori as soon as the experimenter applies the mensurational logic of dichotomous responses to the continuous measurement situation. If the preceding observation seems somewhat distasteful (as well it should), perhaps the decision to make this type of transfer of reasoning would be less blithely made.

\section{REFERENCES}

GORMEZANO, I. Classical condition. In J. B. Sidowski (Ed.), Experimental methods and instrumentation in psychology. New York: McGraw-Hill, 1966. Pp. 385-420.

KIMMEL, H. D. Adaptation of the GSR under repeated applications of a visual stimulus. J. exp. Psychol., 1964, 68, 421-422.

MORROW, M. C., \& KEOUGH, T. E. GSR conditioning with long interstimulus intervals. J. exp. Psychol., in press.

PROKASY, W. F., \& EBEL, H. C. GSR conditioning and sensitization as a function of intertrial interval. J. exp. Psychol., 1964, 67, 113-119.

PROKASY, W. F., \& EBEL, H. C. Three components of the classically conditioned GSR in human subjects. J. exp. Psychot, 1967, 73, 247-256.

PROKASY, W. F., FAWCETT, J. T., \& HALL, J. F. Recruitment, latency, magnitude, and amplitude of the GSR as a function of interstimulus interval. J. exp. Psychol, 1962, 64, 513-518.

NOTE

1. Done under NIMH Grant MH 12262-03. 